\title{
PSICOLOGIA COMO UMA CIÊNCIA SOCIAL ${ }^{1}$
}

\author{
Nikolas Rose \\ University of London, London, United Kingdom
}

\begin{abstract}
RESUMO: A psicologia ocupou um papel importante na sociedade durante o século XX, ajudando a construir o mundo e as pessoas em que nos transformamos. Nesse sentido, constituiu-se como uma "ciência social", promovendo uma "psicologização" das vidas individual e coletiva, inventando e transformando diversas idéias em termos psicológicos. Este texto busca compreender esta caminhada da psicologia, que encontrou seu espaço como uma técnica de regulamentação, um pretenso conhecimento sobre as pessoas com o objetivo institucional de administrá-las, moldálas, reformá-las. Passa pela psicologia social do pós primeira e segunda guerras, com suas pesquisas de atitudes e trabalhos sobre grupos, culminando na noção de empreendimento, construindo e regulando as ações humanas. Termina problematizando a primazia do corpo biológico no século XXI, onde as novas tecnologias de imagem, a psiquiatria biológica, a neuroquímica e a neurobiologia emergem, na mesma medida em que uma "subjetividade cerebral" se fortalece.
\end{abstract}

PALAVRAS-CHAVE: Psicologia Social; história da Psicologia; técnicas de regulamentação.

\section{PSYCHOLOGYAS SOCIAL SCIENCE}

ABSTRACT: Psychology played an important role in society during the $20^{\text {th }}$ century, helping to build the world and the people we became. In that sense, it established itself as a "social science", promoting a "psychologization" of individual and public lives; inventing and transforming several ideas in psychological terms. This text aims at understanding this evolution of psychology which found its space as a regulation technique, a presumed knowledge about people with an institutional objective of managing, shaping and reforming them. It discusses social psychology of post-war periods with its attitude researches and works about groups; reaching its climax with the notion of enterprise, building and regulating human actions. It ends with a discussion over the importance of the biological body in the $21^{\text {st }}$ century, in which new technologies of image, biological psychiatry, neurochemistry and neurobiology emerge at the same time that brainhood is strengthened.

KEYWORDS: Social Psychology; history of Psychology; regulation techniques.

\section{O Século da Psicologia}

O século XX foi certamente o século da psicologia - será que o século XXI será igual? O que quero dizer, quando coloco o século XX como século da psicologia, não é somente que esse foi o século em que a psicologia se transformou em disciplina, com departamentos universitários, professores especializados, diplomas, qualificações e esse tipo de coisa. Nem que esse foi o século em que a psicologia decolou como uma profissão: com corpos profissionais, qualificações, empregos relacionados e muito mais. Penso que, mais do que isso, esse foi o século da psicologia, porque a psicologia através do século XX ajudou a construir a sociedade em que nós vivemos e também o tipo de pessoas em que nos transformamos.

O desenvolvimento da psicologia durante o século $\mathrm{XX}$ teve um importante impacto social em nosso entendimento e tratamento do distress ${ }^{2}$; nas nossas concepções de normalidade e anormalidade; nas nossas tecnologias de regulação, normalização, reforma e correção; no cuidado com crianças e na educação, na propaganda, no marketing e nas tecnologias de consumo, no controle do comportamento humano, do industrial ao militar.

A psicologia e as linguagens da psicologia construíram um senso comum na Europa e na América do Norte, na Austrália, na América Latina e em muitos outros lugares. $\mathrm{O}$ treinamento psicológico afetou profissionais de orientação de crianças, de trabalhos sociais, e mesmo de administração de recursos humanos. No processo, nossas muitas idéias do "self", da identidade, da autonomia, liberdade e da realização pessoal foram reformadas em termos psicológicos. Seres humanos, nessas regiões, vieram a se entender como se fossem habitados por um profundo e interno espaço psicológico, que estaria avaliando-os e agindo sobre eles nos termos dessa crença. As pessoas falam de si mesmas numa linguagem psicológica 
de descrição pessoal - a linguagem da inteligência, personalidade, ansiedade, neurose, depressão, trauma, extroversão, introversão - julgando-se em termos do que penso podermos determinar, quase com certeza, como uma "ética psicológica".

Esse não foi apenas o processo de individualização; isso também inclui a "psicologização" da vida coletiva, a invenção da idéia de grupos, grandes e pequenos, das atitudes, da opinião pública e temas deste tipo. Práticas, da indústria ao exército, podem agora ser entendidas em termos de dinâmicas psicológicas das relações interpessoais. Problemas sociais, do preconceito e luta de grupos até à criminalidade e pobreza, são abalizados em termos psicológicos. Assim, como disse, isso não foi apenas uma questão da psicologia se estabelecer como uma disciplina ou como uma profissão; é uma maneira característica de pensar sobre profissões nas ciências sociais, como disciplinas que tentam exercer sua autonomia como profissões e manter o controle de determinadas técnicas. Mas, com a psicologia não foi assim. A psicologia foi uma disciplina muito generosa, ela se doou para todos os tipos de profissões, da polícia a comandantes militares, numa condição de fazê-los pensar e agir, pelo menos de alguma maneira, como psicólogos.

Conforme entramos no século XXI, talvez queiramos refletir sobre esse processo; talvez o poder da psicologia, como uma maneira de entender e administrar todos esses assuntos, esteja enfraquecendo. Talvez esse profundo espaço psicológico que se abriu em nós esteja começando a se achatar, enquanto nossos descontentamentos agem diretamente no cérebro. Então, será o século XXI o século da psicologia? - isso é o que pergunto na minha pesquisa atual. Mas aqui, como eu, nostalgicamente, disse, apenas quero retomar algumas considerações que fiz sobre a psicologia vinte anos atrás; e estou ansioso para saber se vocês pensam que elas ainda valem. Talvez ainda apontem para alguma coisa significativa sobre o papel da psicologia como uma ciência social, e, quem sabe, até como uma ciência política.

\section{Como Fazer a História da Psicologia?}

Todo aluno de psicologia conhece a expressão "a psicologia tem um longo passado, porém uma história curta", como Edwin Boring assinalou de forma bem sucinta. Um longo passado - séculos de reflexão sobre a vida mental humana, voltando aos gregos, estabelecem a credibilidade da disciplina. Assim, vocês que estão estudando psicologia, estão estudando uma longa e honrada tradição, de acordo com Boring. Ainda, uma história curta, que data da adoção de metodologias empíricas no século XIX, o que levou ao desenvolvimento de uma ciência real da mente, vida e comportamento humano. Esse é, na verdade, o mito fundador da disciplina psicologia. Mas issoé fundamentalmente incorreto. A psicologia como uma ciência moderna não foi formada nos corredores tranqüilos da academia, nem no empirismo dos aventais brancos do laboratório e do experimento. Na verdade, a psicologia começou a se formar em todos aqueles locais práticos que tomaram forma durante o século XIX, no qual problemas de conduta coletiva e individual humanas eram de responsabilidade das autoridades que procuravam controlá-las - nas fábricas, na prisão, no exército, na sala de aula, no tribunal...

A psicologia, inicialmente, tomou forma não como uma disciplina ou uma área profissional, mas como uma cadeia de pretensões de conhecimento sobre pessoas, individual e coletivamente, que permitiria que elas fossem melhor administradas. Por essa razão, essa não é a "psicologia aplicada" - os vetores não foram de um conhecimento formado na academia para o campo das aplicações, mas o contrário. Similarmente, os vetores do desenvolvimento da psicologia não foram do normal para o anormal, mas fizeram o caminho inverso: um conhecimento da normalidade, e das normas da normalidade, derivado de um interesse na anormalidade. Por exemplo, a idéia de inteligência, que seria um foco da psicologia durante a primeira metade do século XX, surgiu de esforços para identificar os indivíduos de reduzida capacidade mental e encaminhá-los para instituições apropriadas, escolas ou colônias especiais. O mesmo pode ser dito da personalidade e de quase todos os "conceitoschave" da disciplina.

\section{Mentes Calculáveis e Indivíduos Administráveis}

Inicialmente, a psicologia se constituiu como uma tecnologia de individualização, quer dizer, emergiu mais como uma "ciência positiva" do que como uma subcategoria da filosofia quando mudou suas responsabilidades da teoria geral da mente para um campo prático: a criação de mentes calculáveis e de indivíduos administráveis. Isso ocorreu em um espaço problemático específico, formado por demandas crescentes de que os indivíduos deveriam ser administrados, ou distribuídos em regimes particulares, tarefas ou tratamentos, de acordo com suas habilidades - na escola, no trabalho, no exército, no sistema de justiça.

Quando Cyril Burt ${ }^{3}$ foi indicado para seu posto em 1913, Sir Robert Blair ${ }^{4}$, então oficial chefe da educação na Inglaterra, o anunciou como "o primeiro psicólogo oficial do mundo". Sua tarefa principal pode parecer estranha para nós: examinar crianças do ensino fundamental vistas como enfraquecidas mentalmente. Em seu livro de 1921, Mental and scholastic tests, Burt conta a seus leitores uma parábola:

Na história de Rasselas, príncipe de Abyssinia, está descrito como uma vez um bárbaro tolo tentou voar. Ele subiu, abriu as asas, se soltou da beirada, e logo caiu de cabeça em um lago. Mas suas asas, que fa- 
lharam em sustentá-lo no ar, o mantiveram flutuando quando ele atingiu a superfície do lago. $\mathrm{O}$ episódio foi escrito como uma alegoria, e tem a intenção de desmentir o estereótipo de que o destino dos defeituosos em geral é determinado por sua inaptidão. Em uma atmosfera traiçoeira e estreita, em uma altitude difícil e atordoante onde homens altamente civilizados, assistidos pelo mais novo maquinário de uma comunidade altamente civilizada, sozinhos podem viajar de maneira segura, e sozinhos devem se aventurar a altos vôos, lá, os mais simples, menos afortunados e inconscientes de sua debilidade, bem menos equipados, irão ao encontro de sua ruína. Mas se estes encontrarem um plano denso e elástico o bastante e, ainda, mais flutuante e menos variável, podem imaginar, embora mecanicamente, que estão se apoiando sem nenhuma ajuda. Em um ambiente ele cai, em outro ele pode flutuar. Ele está lá, como dizemos, no seu elemento. (Burt, 1921, p. 172).

Cada um em seu elemento - um sonho nobre, talvez relembrando um outro: de cada um de acordo com suas habilidades, para cada um de acordo com suas necessidades. A chave da tecnologia de Burt para atingir esse objetivo foi a invenção da norma - aquele pequeno e peculiar termo que condensa, em uma palavra, idéias do normal, do regular, do significado estatístico, do desejável, do saudável... Para os psicólogos, a norma não foi derivada de nenhum conhecimento do funcionamento orgânico da mente humana, como foram as normas da medicina em relação à regulamentação do corpo. As normas psicológicas derivam das normas requeridas pelas instituições - do sistema escolar, da indústria, das forças armadas e de todos os lugares. A forma psicológica da norma emparelha esses requerimentos com as normas de variação estatística e as leis de grandes grupos, alinhando também regras de desejo sócio-político e institucional com a demanda da teoria estatística. George Canguilhem, talvez o principal autor da epistemologia histórica, reforça isso em seu estudo, The normal and the pathologic 5: "É a própria vida, e não o julgamento médico, que faz do normal biológico um conceito de valor e não de realidade estatística”. Por essa razão, Canguilherm gosta de citar Leriche: "Saúde é vida no silêncio dos órgãos". Mas para a psicologia, é perdoável pensar que saúde era, como um dia foi, meramente vida no silêncio das autoridades: isso está conectado a um projeto de normalização sem referência às normas do seu objeto, uma teoria patológica sem uma teoria de normalidade.

É claro que uma teoria assim seria muito simples. A psicologia se forma como um híbrido entre esses projetos administrativos e projetos filosóficos mais antigos. Esse foi o tema das reflexões de Canguilhem em sua palestra What is Psychology? ${ }^{6}$, ministrada na Sorbonne, em Paris, em 1956. Ele sugeriu que a psicologia, como a Sorbonne, está posicionada entre duas rotas possíveis.
Quando alguém sai da Sorbonne, pode seguir em uma de duas direções. Se essa pessoa tomar o caminho que sobe a montanha, chega ao Pantheon onde os mais sábios filósofos franceses estão enterrados. Por outro lado, o caminho que desce a montanha leva à delegacia de polícia.

O trabalho de Burt, originalmente, era conectado a uma responsabilidade sócio-política sobre a degenerescência, e em particular sobre as conseqüências para a sociedade da existência e reprodução daqueles de reduzida capacidade mental: um grupo de indivíduos que, para alguém sem um olho clínico, eram quase imperceptíveis entre as pessoas normais, mas, na verdade, faziam parte da extensa família daqueles de pouca serventia para a sociedade - os tuberculosos, os portadores de sífilis, os alcoólatras, os doentes mentais, as prostitutas e os que não podiam trabalhar - e sua proliferação excessiva poderia, em poucas gerações, colocar em risco a qualidade do restante da população. Aqui não é o lugar para falar sobre alianças eugênicas entre os psicólogos anteriores, do estudo da inteligência e dos testes psicológicos: essa história é bem conhecida (Rose, 1985).

Os testes psicológicos eram inicialmente requeridos e usados por aqueles que queriam encontrar a verdade sobre o problema mental. O significativo aqui não é apenas a aspiração de diferenciar pessoas de acordo com suas habilidades mentais, mas a invenção de tecnologias para isso, notavelmente "o teste". Phillip Ballard disse em 1920, a respeito de Alfred Binet, o inventor original do dispositivo para identificar aqueles que a reduzida capacidade mental tornaria incapazes de aprender as lições da escola regular:

A glória de Binet não é ter agrupado um conjunto de testes heterogêneos para a detecção de mentes deficientes, e sim ter inventado uma escala. Lembrando assim, Saul, o filho de Kish, que saiu para procurar cinzas e encontrou um reino. (Ballard, 1920).

A idéia central aqui foi que a psicologia se moveu, no final do século XIX, da tecnologia investigativa do experimento para a tecnologia julgadora do teste. O teste é um novo tipo de exame que não é clínico nem pedagógico, como em exames de qualificação para universidades ou para serviços públicos; é na verdade modelado para relacionar uma pontuação a um indivíduo. O teste é uma maneira de materializar a mente, é parte de uma mudança maior na individualização, partindo de um olhar focado no corpo para um olhar focado em um espaço interior. Tentativas anteriores de médicos para descobrir a verdade do problema mental focavam o corpo - as crianças, apenas com roupas de baixo, desfilavam na frente dos médicos, cujo olhar treinado deveria identificar o estigma do defeito no formato da face, na postura e no andar, na proporção dos membros e assim por diante. $\mathrm{O}$ problema daqueles de capacidade mental reduzida pare- 
cia ser que seus corpos não eram de fácil leitura. Daí, a lógica do teste. A diferença não é mais escrita na superfície do corpo e, sim, em um domínio interior, e o teste psicológico é uma maneira de transformar o invisível em visível, calculável e administrável. O teste torna a diferença visível de uma forma particular - através de números, e especificamente, na forma de um único número: o resultado geral. Tais números têm grande poder, e incorporam a autoridade da objetividade. A "caixa-preta" do resultado transforma questões de valores e avaliação em questões técnicas sobre a construção, confiança e validação do teste. Crianças movem-se, transformam-se, tornando difícil a acumulação de informação e cálculo a seu respeito. Mas o teste funciona como um mecanismo de inscrição para capturar esses comportamentos efêmeros, qualidades passageiras e capacidades variáveis do seres humanos, levando-os serem pensados como objetos “dóceis". Os resultados dos testes - tabelas, gráficos -, como móbiles imutáveis, possibilitam a estabilização, o acúmulo de informação sobre o objeto do teste. Eles permitem sua normalização, esquematização e deliberação no ambiente tranqüilo do escritório dos psicólogos, que pode assim se transformar no que Bruno Latour chama de "centro de cálculo". Decisões podem ser tomadas a partir deste centro e de instruções vindas dele, possibilitando que os sujeitos sejam administrados nesse sentido - distribuídos em torno da variedade de papéis disponíveis, classes, tarefas no exército ou na indústria, ou encaminhadas para a escola ou hospital corretos dentro de um arquipélago de instituições. Projetos para individualização, acesso e administração do indivíduo no sentido de suas capacidades psicológicas espalham-se além do intelecto em direção à personalidade, e também para todas as práticas nas quais os indivíduos deveriam ser administrados em relação às suas diferenças. A psicologia é formada, assim, como uma competência em diferenças individuais, em diferenciação individual.

É importante, entretanto, ser claro sobre uma coisa. As tecnologias humanas, nas quais a psicologia estava envolvida, não eram tecnologias desumanas. A psicologia ganhou seu poder na indústria, na escola, no exército, na prisão, precisamente pela necessidade desses órgãos de administrar seres humanos à luz de um conhecimento de sua natureza, e, fazendo isso, ajudou a dar uma nova legitimidade à autoridade: a autoridade deixou de ser arbitrária. O trabalho de F. W. Taylor e o tipo de organização que ficou conhecida como taylorismo é um exemplo, pois, apesar de às vezes ser criticado como um projeto para controlar o trabalhador como se fosse uma máquina, o apelo de Taylor à racionalidade foi na verdade uma resposta explícita a uma crise de legitimidade da organização dos Estados Unidos.

Foi um processo de auto-afirmação. Cada uma dessas instituições, onde tal distribuição psicológica era prati- cada, se transforma um pouco em um laboratório psicológico, onde indivíduos podem ser observados, controlados, testados em nome da eficiência da organização. E o que pode ser observado, nesse processo, é a verdadeira produção de novas identidades em potencial. Com isso, quero dizer que podemos observar uma mudança dos termos pelos quais os indivíduos não somente são julgados por outros, mas também nos termos pelos quais eles entendem, julgam e agem sobre si mesmos. Para mim, o que está em jogo aqui não é a questão psicológica de produção de subjetividades, uma questão de alterar as maneiras pelas quais indivíduos se "relacionam com seu 'eu". Para mim, isso parece ser uma questão aberta à investigação histórica - uma história das relações que os indivíduos têm consigo mesmos. A psicologia nasceu, como uma disciplina, dentro de uma variedade de projetos políticos para o controle de indivíduos: teve uma vocação social desde o início. Aqui está Burt de novo em 1927:

\begin{abstract}
Como muitos avanços na ciência teórica, a anexação desse novo campo [da psicologia do indivíduo] pode ser vista como pressão das necessidades práticas. As psicologias da educação, da indústria e da guerra, o estudo do criminoso, do deficiente e do insano, dependem para seu desenvolvimento de uma boa análise das diferenças individuais; e a investigação dos problemas mais práticos já começou a pagar sua dívida, fornecendo novos dados, de grande valor para a ciência mãe. Por fim, nós vemos o nascimento do membro mais novo na lista das ciências - a psicologia do indivíduo... Almeja precisão quase que matemática, e propõe nada menos do que o controle dos poderes mentais. (p. 5).
\end{abstract}

\section{Psicologia como Ciência Social}

Considera-se que a conexão entre a cultura política moderna e a psicologia reside em seu "individualismo" compartilhado, e muitos já sugeriram que esta é a explicação para o forte individualismo de grande parte da psicologia nas culturas individualistas do ocidente. Foi certamente como uma "ciência do indivíduo" que a psicologia encontrou, a princípio, um lugar em meio às técnicas de regulamentação. Segundo a racionalidade típica de democracias liberais de governo, noções abstratas da liberdade do indivíduo são acompanhadas pela proliferação de práticas racionalizadas que procuram moldar, transformar e reformar indivíduos. Assim, não era apenas a ética do individualismo, mas também as práticas de individualização na prisão, na fábrica, na escola e no manicômio que forneciam condições-chave para disciplinar a psicologia. A psicologia acharia seu lugar em todos esses sistemas nos quais indivíduos deveriam ser administrados, não por um poder arbitrário ou negligente, mas partindo de julgamentos que buscavam objetividade, neutralidade, e desta maneira, efetividade. Isso forneceria uma tecnologia para tornar o 
individualismo utilizável como um conjunto de programas específicos para a regulação da existência.

Ainda assim, nesse momento individualizante, a psicologia era uma ciência "social", uma ciência com vocação social, organizada em torno de objetivos sociais, como vimos em suas conexões com as idéias de degenerescência e eugenia, e sua vontade de detectar os indivíduos de reduzida capacidade mental. Mas existe também um outro sentido pelo qual a psicologia era uma ciência "social" - no período de antes e durante a Segunda Guerra Mundial e logo depois dela, a psicologia deveria direcionar-se para os processos inerentes às coletividades humanas, grandes e pequenas. Deveria procurar pensá-las e conceituá-las a fim de administrar indivíduos e organizações. Nesse sentido ampliado, então, a psicologia se transformaria em uma verdadeira ciência social. Deixem-me falar, portanto, um pouco sobre dois exemplos: a Democracia e "o Grupo".

\section{Democracia}

A psicologia social que foi escrita nos anos 30, 40 e 50 faz referência freqüente à democracia. $\mathrm{O}$ artigo clássico de Gordon Allport sobre a história da psicologia social moderna, na primeira edição do Handbook of Social Psychology em 1954, afirma que "as raízes da psicologia social moderna estão no solo distinto dos pensamentos e da civilização do ocidente", sugerindo que a psicologia social requer a rica mistura das ciências naturais e biológicas, a tradição de livre investigação e "uma filosofia e ética da democracia". (Allport, 1954). Os estudos famosos de Lewin, Lippitt e White sobre estilos de liderança, desenvolvidos de 1938 a 1942 na Estação de Pesquisa do Bem-Estar da Criança em Iowa, procuraram demonstrar as diferenças entre grupos criados experimentalmente em uma atmosfera democrática e outros numa atmosfera autocrática ou de laissez-faire - as diferenças encontradas foram sempre em prol da democracia (Lewin, Lippitt, \& White 1939; Lippitt, 1939, 1940). George Gallup e S. F. Rae intitularam seu primeiro livro sobre a opinião pública, publicado em 1940, de The pulse of democracy, e argumentaram que, em uma sociedade democrática, as opiniões da maioria devem ser vistas como o último tribunal para assuntos políticos e sociais (Gallup \& Rae, 1940, p. 15). J. A. C. Brown, em seu livro-texto publicado primeiramente em 1954 e com várias reedições, The Social Psychology of industry ${ }^{7}$, tem muito a falar sobre democracia, concluindo que "uma democracia industrial genuína pode ser baseada apenas na cooperação inteligente de grupos primários de trabalho com administração de mentes responsáveis" (Brown, 1954, p. 301).

$\mathrm{O}$ que devemos fazer com essas referências à democracia? Elas são apenas um tanto quanto retóricas? Minha resposta é: não. Regular cidadãos democraticamente significa regrá-los através de suas relações com o outro, conhecendo e modelando essas relações de acordo com uma concepção de como elas funcionam - alinhando o governo com a dinâmica social daquilo que será governado. Como Gordon Allport afirmou:

A primeira Guerra Mundial ... seguida pela expansão do Comunismo, pela grande depressão dos anos 30, pela ascensão de Hitler, pelo genocídio dos judeus, por protestos raciais, pela Segunda Guerra Mundial e pela ameaça atômica, estimulou todos os ramos de ciência social. Um desafio especial caiu sobre a psicologia social. A pergunta foi lançada: Como é possível preservar os valores da liberdade e dos direitos individuais em condições de pressão e regulamentação? A ciência pode ajudar a encontrar uma resposta? Essa questão desafiadora levou a uma explosão de esforços criativos que acrescentaram muito ao nosso entendimento dos fenômenos da liderança, opinião pública, rumores, propaganda, preconceito, mudança de atitude, moral, comunicação, tomada de decisões, relação entre raças e conflitos de valores. (1954, p. 2)

A psicologia social estava lá para criar um vocabulário para o entendimento desses problemas que atrapalhavam a democracia. Para avaliar as possibilidades de resolvê-los de maneira democrática. Para fornecer os meios para a criação de propostas resolutivas desses problemas, por um lado de acordo com o conhecimento racional científico e, por outro lado, de acordo com os valores democráticos da sociedade liberal, pluralista e individualista do ocidente. E para contribuir com as tecnologias que iriam procurar dar efeito a essas novas maneiras de governar. Allport cita Giambattista Vico na abertura da sua revisão histórica de psicologia social: “ $\mathrm{O}$ governo deve se adequar à natureza dos homens governados" (Vico, 1725, conforme tradução de 1848, citada por Allport, 1954, p. 1). Para a psicologia social, como para a filosofia política, a natureza social do homem deve ser conhecida para que ele seja adequadamente governado. A psicologia social proporciona tanto a tecnologia humana quanto a intelectual para possibilitar que o governo democrático opere.

Atitudes foram o primeiro conceito-chave. O desenvolvimento da "ciência das atitudes" exemplifica a maneira como problemas de governo são reformados nos termos da linguagem nascente da psicologia social, com o objetivo de fazê-los mais maleáveis para que sejam encontradas soluções. "Atitude" apareceu pela primeira vez em The polish peasant (1918), de Thomas e Znaniecki: os autores argumentavam que a ciência social precisava responder à desorganização gerada pelas mudanças sociais através do desenvolvimento de técnicas de controle racionais, baseadas em um conhecimento que daria base àquilo que chamaram de "tecnologia social", que aplicaria o conhecimento acumulado pelos cientistas sociais a situações práticas: 
É teoricamente possível saber quais influências sociais devem ser aplicadas a certas atitudes já existentes, com o objetivo de criar novas atitudes, e quais atitudes devem ser desenvolvidas levando em consideração certos valores sociais já existentes, com o objetivo de fazer o indivíduo ou o grupo produzir novos valores sociais. Não existe um único fenômeno em toda a esfera da vida humana que o controle consciente não consiga alcançar mais cedo ou mais tarde. (1918, p. 66-67).

Por volta de 1918, atitudes se tornaram um tema chave, um espaço para pensar e agir sobre os problemas das relações de indivíduos e grupos, parte da tentativa de desenvolver tecnologias para o controle consciente da conduta social humana baseado em conhecimento científico. Mas isto não ocorreu até 1928, quando Thurstone proclamou, orgulhoso, que "atitudes podem ser controladas" e inaugurou uma série de invenções para tornar o subjetivo objetivo, o intersubjetivo calculável, permitindo que cada indivíduo fosse colocado numa escala de atitudes, podendo assim ser comparado com outros. Atitudes, para Floyd Allport, não eram anêmicas: elas eram cheias de vitalidade, desejo, ódio, amor e paixão. Como ele afirmou em 1935: "Para a explicação do preconceito, lealdade, patriotismo, comportamento de multidão, controle pela propaganda, nenhuma concepção anêmica de atitude será suficiente".

A concepção de atitude seguiria junto, nas primeiras décadas do século XX, com as políticas da sociedade americana, que colocaram grande fé no controle de todas as áreas da vida social por competentes e racionais engenheiros científicos, administradores e gerenciadores (Miller \& O'Leary, 1989). A reforma progressista ameaçou os ideais democráticos devido a uma administração municipal corrupta, e a uma concentração de poder incontável nas mãos das grandes corporações e no setor financeiro. $\mathrm{O}$ conhecimento das ciências sociais era uma contribuição para tornar essas ameaças à democracia administráveis, com seus apelos à objetividade, racionalidade, profissionalismo e neutralidade. Isso iria reconciliar as metas da eficiência administrativa com as da democracia - a autoridade seria exercida não através de capricho arbitrário ou interesses parciais, mas, sim, através da exatidão científica. Uma grande quantidade de espaços no mundo intersubjetivo seria mapeada através da noção de atitudes: atitudes de proprietários de hotel e restaurante para com chineses, atitudes de universitários para com negros, judeus, atitudes de empregados para com seu trabalho, chefes e muito mais. $\mathrm{Na}$ época da deflagração da Segunda Guerra Mundial, a tecnologia de atitudes foi usada para suprir a promessa de uma tecnologia social racional e de acordo com os valores da democracia pelos quais a guerra aconteceu.

A idéia de atitude era também chave para a invenção da "opinião pública" - "sentindo o pulso da demo- cracia”, como George Gallup colocou. O público nem sempre foi pensado como um fator de opinião, e certamente não como uma parte que deveria ser ouvida - os debates do início do século XX sobre democracia, nos Estados Unidos, eram cheios de preocupações em relação às multidões, às massas e aos perigos de tais aglomerações para a democracia. No entanto, gradualmente um argumento diferente prevaleceu: a opinião pública era vital para a democracia, mas não deveria ser formada por suposições uniformes de políticos ou reivindicações não representativas de grupos de pressão. Como, então, seria conhecida a verdadeira opinião do público? Foi nos anos 30 que se demonstrou o valor da amostra grande e sistemática de opiniões, e a ciência da pesquisa de opinião foi validada; como Floyd Allport afirmou, no artigo de abertura da primeira edição de Public Opinion Quarterly, opinião pública não tinha nada a ver com as antigas falácias de mentes coletivas, mas era o resumo de opiniões específicas de indivíduos sobre assuntos ou pessoas em particular. E, para Gallup, a pesquisa de opinião pública forneceu dupla conexão entre cidadãos e seus representantes a favor de uma democracia, o que era crucial.

Não há tempo aqui para explorar em detalhes os caminhos pelos quais a medição e a administração da moral e da opinião se tornaram cruciais na Segunda Guerra Mundial - a moral do inimigo, a moral do país, os meios de ataque ao primeiro pelas técnicas psicológicas de guerra e os meios de sustento do segundo pela propaganda e coisas do gênero. Um leque de estudos, documentos e livros se seguiu, desenvolvendo teorias de propaganda, rumores e mudança de atitudes - a mente do público havia se tornado um domínio acessível ao conhecimento, cálculo e governo de uma maneira que seria crucial para o governo das democracias nos anos do pós-guerra.

Talvez se possa argumentar que isso é apenas o uso de técnicas originais para descobrir o que sempre esteve lá - atitudes, opiniões. Eu discordaria. As ciências sociais, incluindo a psicologia e a psicologia social, na verdade criam fenômenos. Elas trazem novos domínios a serem conhecidos, registrados e administrados. E elas mudam as maneiras como os indivíduos se relacionam consigo mesmos. Cidadãos, agora, têm "atitudes", que discutem e justificam, controlam e mudam. E cidadãos têm opiniões: nós aprendemos a ter opinião.

\section{O Grupo}

Tenho tempo para mais um breve exemplo - a invenção do grupo. É claro, você vai dizer, os seres humanos sempre cooperaram com outros em grupos grandes e pequenos. Mas foi nos anos 30 que o grupo foi descoberto como um campo a ser estudado, registrado, calibrado e administrado. Como eu escrevi, há quase 20 anos atrás: 
O grupo deve existir como um intermediário entre o indivíduo e a população, deve habitar o mundo desalmado da organização e dar, a esse mundo, sentido subjetivo na visão do empregado; isso irá suprir as necessidades sociais do atômico e fragmentado 'self', isolado com o aparecimento da divisão do trabalho e o declínio da comunidade, isso irá explicar problemas e poderá ser mobilizado para o bem, poderá provocar danos na sua forma totalitária e contentamento e eficiência na sua forma democrática. No meio do grupo, um novo lugar foi encontrado onde a administração, à luz da capacidade psicológica, poderá chegar ao alinhamento com os valores da democracia.

O grupo foi primeiramente descoberto na fábrica a fábrica e o local de trabalho vêm há tempos sendo locais-chave para a construção das subjetividades coletivas e individuais. Nos anos 30, pode-se observar uma mudança de um foco no trabalhador individual, e em sua adaptação ou não adaptação - que seria higiene mental, alocação eficiente de mão-de-obra, seleção, orientação vocacional e tratamento de neuroses psicológicas individuais - para as relações coletivas do grupo de trabalho. Os mais famosos estudos foram os de Elton Mayo, Hawthorne works of the Western Electric Company, entre 1923 e 1932. Para Mayo, o significativo não era nem as exigências objetivas e as características do processo de trabalho - níveis de luz, horas de trabalho e etc. - nem mesmo as não-adaptações e neuroses psicológicas dos trabalhadores individualmente, mas as relações humanas da empresa: a vida informal de grupo que ela construiu e as relações subjetivas internas que ela compôs. Produtividade, eficiência e contentamento deviam agora ser entendidos em termos das atitudes dos trabalhadores com seu trabalho, seus sentimentos de controle sobre seu ritmo e ambiente de trabalho, seu senso de coesão dentro de seu pequeno grupo, suas crenças sobre a preocupação e entendimento que os patrões tinham pelo seu valor individual e seus problemas pessoais.

Uma nova gama de tarefas emergiu para ser entendida pelo conhecimento e administrada dentro da fábrica. As características subjetivas da vida coletiva puderam ser conhecidas por meio de entrevistas - os pesquisadores de Hawthorne realizaram umas 20.000 dessas que acabaram sendo utilizadas, não para fornecer informação objetiva, e sim para serem caminhos para a vida emocional da fábrica, permitindo que os pesquisadores interpretassem o aspecto psicológico das reclamações, e as enxergassem como sintomas de situações sociais que precisavam ser entendidas e administradas para criar uma harmonia organizacional. Comunicação, aconselhamento e muitas outras eram técnicas através das quais a administração poderia criar a harmonia interna, que era a condição para uma fábrica feliz e produtiva. Interações humanas, sentimentos e pensamentos, as relações psicológicas do indivíduo com relação ao grupo emergiram como um novo domínio para a administração (Roethlisberger \& Dickson, 1939).

Existiram muitos outros caminhos para o descobrimento do grupo. Muzafer Sherif encontrou normas de grupo em seus estudos das relações de grupo no experimento Robbers Cave, conduzido com os escoteiros americanos no campo de Oklahoma, e descobriu como eles poderiam ser artificialmente manipulados para criar hostilidade - o grupo aparecia como um ponto de perigo em potencial. Kurt Lewin descobriu um grupo mais virtuoso em suas aplicações experimentais da teoria de campo, e procurou mostrar que os valores da democracia poderiam ter uma base científica, a superioridade da democracia sobre outros modos de exercer autoridade social podendo ser demonstrada em um cenário experimental e generalizada para a vida organizacional e para culturas como um todo. Democracia seria não apenas comprovadamente vantajosa, mas poderia também ser ensinada. Lewin e Bavelas descrevem "um rápido 'retreinamento' de líderes medíocres transformando-os em eficientes e democráticos líderes". Isso não apenas fez os líderes de grupos ficarem mais sensíveis às possibilidades da liderança, mas eles também "sentiram nitidamente sua própria calma e desenvoltura, depois de descobrirem que a disciplina do grupo não dependia mais da sua vigilância constante" (Bavelas \& Lewin, 1942). No período pós-guerra, essa descoberta do grupo como um mecanismo de treinamento foi institucionalizada no National Training Laboratories in Group Development, que Lewin inaugurou em 1947. Parecia que treinar indivíduos para serem líderes melhores também fazia com que eles se sentissem pessoas melhores, que se poderia completar alguém como pessoa ao torná-lo um administrador mais eficiente e um líder mais democrático.

Este trabalho está ligado à descoberta inglesa de um tipo diferente de grupo através do trabalho da Clínica Tavistock e do Instituto Tavistock de Relações Humanas. Grupos haviam sido descobertos nos métodos de tratamento nos hospitais militares por Tom Main e Maxwell Jones, mas talvez mais notavelmente por Wilfred Bion, cujas "experiências em grupos" se tornaram o texto fundador de uma nova maneira de induzir dinâmicas de interação de grupos para a awareness ${ }^{8}$ dos participantes: experimentando as dinâmicas de "grupos sem líderes", e participando do processo interpretativo, eles se tornariam, ao mesmo tempo, melhores em seus trabalhos, quaisquer que fossem, e melhores entendedores de si mesmos. Os "grupos sem líderes" se tornaram um poderoso método de treinamento em grupos grandes e pequenos de terapia, de conceituação de problemas do trabalho, de reforma da estrutura da autoridade no local de trabalho, e, com o trabalho de Eric Trist, Elliot Jacques e muitos outros, se tornaram uma maneira de tratar os assuntos de produtividade na indústria partindo da 
Tennessee Valley Authority ${ }^{9}$, nos Estados Unidos, até a Unilever ${ }^{10}$ no Reino Unido. Resumindo, os grupos estavam em todos os lugares.

\section{A Psicologia da Empresa ${ }^{11}$}

Em 1967, Dorwin Cartwright e Alvin Zander ainda podiam introduzir a terceira edição de sua descrição compreensiva de Group dynamics: Research and theory ${ }^{12} \mathrm{com}$ uma referência explícita à democracia:

A força da sociedade democrática vem do efetivo funcionamento da multiplicidade de grupos que ela possui. Seu recurso mais valoroso são os grupos de pessoas encontrados em suas casas, comunidades, escolas, igrejas, negociações, auditórios de sindicatos e em várias filiais de governo. Agora, mais do que nunca, é reconhecido que essas unidades realizarão bem suas funções se os sistemas maiores trabalharem com sucesso. (Cartwright \& Zander, 1967, p. VII).

Mas talvez o apogeu do grupo já tivesse acabado. Uma nova relação estava tomando forma entre os problemas aparentes de inúmeras práticas, as aspirações do governo, a subjetividade do indivíduo e a capacidade da psicologia. Essa nova relação é melhor resumida em uma palavra - Empresa.

Através dos anos 80, a pressuposição do indivíduo autônomo - que escolheu o "self” livre como valor, base ideal e objetiva - serviu para legitimar a atividade política, e preencheu as mentalidades políticas do Reino Unido, dos Estados Unidos e até de alguns países da "velha Europa", assim como aqueles radicais que eram chamados de "Europa do Leste". Quase todos os problemas do passado foram reduzidos à falta de iniciativas. A idéia de empresa liga uma sedutora ética do "self', uma poderosa crítica à realidade institucional e política contemporânea e um design aparentemente coerente para a transformação radical de planejamentos sociais contemporâneos. Nos textos de "neoliberais" como Hayek e Friedman, o bemestar das existências política e social deve ser garantido não por planos centralizados e burocracia, mas através de atividades "empreendedoras" e escolhas de entidades autônomas - negócios, organizações, pessoas -, cada uma se esforçando para maximizar sua própria vantagem e promovendo novos projetos por meio de cálculos de estratégias e táticas individuais, locais, custos e benefícios (Friedman, 1982; Hayek, 1976).

As formas de razão política que almejavam uma cultura de empreendimentos estavam de acordo com um valor político vital para certa imagem do "self". A imagem de um "self empreendedor" era potente porque não era uma posse de "direito", mas ressoava com pressupostos amplamente presentes em se tratando do "self", incorporado em nossa linguagem para fazer pessoas pensantes, e em nossos ideais de como as pessoas devem ser. Empresa não apenas designa um tipo de organização apropriado para organizações industriais e de negócios - unidades individuais competindo com outras no mercado -, mas também fornece uma imagem original para um modelo de atividade a ser encorajado em locais que tinham anteriormente operado de acordo com lógicas bem diferentes: a escola, a universidade, o hospital, o consultório do $\mathrm{GP}^{13}$, os vários exércitos da guerra social, até mesmo a família. Os problemas em cada domínio eram problematizados em termos da falta de empreendimento que habitava aquelas entidades: isso era o exemplo máximo de suas fraquezas e de suas falhas. Elas deveriam ser reconstruídas, promovendo-se e utilizando-se as capacidades de iniciativa de cada uma, encorajando-as a se conduzirem com ousadia e vigor, a usarem o cálculo para sua própria vantagem, para guiá-las rigorosamente e a aceitar riscos na busca dos objetivos.

A empresa ganhou dos especialistas em vida organizacional uma forma "tecnológica", construindo as relações humanas, através da arquitetura, da carga horária, dos sistemas de supervisão, dos esquemas de pagamento, dos currículos e coisas do gênero, para alcançar a economia, eficiência, excelência e competitividade. Práticas reguladoras foram transformadas para incorporar a pressuposição do "self empreendedor", esforçando-se por satisfação, excelência e conquistas. Por essa razão, o vocabulário da empresa liga a retórica da política e de programas reguladores às capacidades de "controle do 'self" dos próprios sujeitos. A empresa forjou um novo "link" entre as maneiras pelas quais somos governados por outros e as maneiras pelas quais devemos nos governar. Designou uma coleção de regras para a condução da existência cotidiana de uma pessoa: energia, iniciativa, ambição, cálculo e responsabilidade pessoal. O "self empreendedor" faria de sua vida um empreendimento, projetaria um futuro e procuraria adequar-se na intenção de se tornar aquilo que desejasse. Empresa designa uma forma de regular que é intrinsecamente "ética": um bom governo é aquele baseado nas maneiras pelas quais as pessoas se governam. O "self” é para aspirar autonomia, para esforçar-se para alcançar satisfação pessoal em sua vida na terra, para interpretar sua realidade e destino como uma questão de responsabilidade individual, enfim, encontrar significado na existência moldando sua vida através de escolhas.

Essas maneiras de se pensar sobre "selves", e de julgá-los, estavam ligadas a certas maneiras de agir sobre "selves". A orientação dos "selves" não era mais dependente da autoridade da religião ou moralidade tradicional; estava alocada a "especialistas da subjetividade" que transfiguraram questões existenciais sobre o propósito da vida e o significado do sofrimento em questões técnicas, em maneiras mais efetivas de se administrar o mal- 
funcionamento e melhorar a "qualidade de vida". No governo do "self empreendedor", através das duas últimas décadas do século XX, em casa e no trabalho, em universidades e em shoppings, no escritório de trabalho e no complexo médico, a psicologia - sua linguagem, suas explicações, seus julgamentos, suas competências - mais uma vez provou seu valor.

\section{Conclusão: Ainda o Século "Psi”"?}

O tipo de análise que sugeri não é uma crítica à psicologia - não é minha intenção dizer que é corrupta, que serve ao poder ou que é parte de estratégias de dominação e exploração. Também não quero substituir uma psicologia por outra, mais verdadeira, mais humana, ou mais científica. Eu meramente apontei as relações recíprocas entre essas maneiras de nos entendermos conceitualmente, nos administrarmos na prática, e trabalharmos sobre nós mesmos eticamente. Conforme entramos no século XXI, é relevante perguntar se o novo século ainda será o século da psicologia - o século "psi".

Sugeri em outro texto que o "self" psicológico "profundo", inventado durante o século XX - o interior profundo que habita cada um de nós, o depósito da história de nossas vidas, o assento dos nossos desejos, o local de nossos prazeres e frustrações, o alvo do conhecimento, invenção, administração e terapia, a base de nossa ética - que este espaço profundo está se achatando. Novas e diretas relações estão sendo estabelecidas entre nossos pensamentos, sentimentos e desejos, nossa normalidade e nossa patologia e nossos "cérebros", este visto como um órgão de carne a ser anatomizado e entendido em nível molecular. O corpo biológico é agora crescentemente tido como o assento de nossos problemas e o alvo de trabalhos éticos de melhoria do indivíduo. Na visão de alguns, ao menos, nós ultrapassamos o dualismo cartesiano em cima do qual a psicologia se apoiava - mente é apenas o que o cérebro faz.

Das novas tecnologias de imagem - estudos de tomografias cerebrais de neurônios, in vitro e in vivo -, aos avanços na psiquiatria biológica, neuroquímica e genoma, o cérebro vem sendo recriado como o depósito de tudo o que antes estava alocado na mente. Podemos antecipar o enfraquecimento da psicologia - ou pelo menos sua transformação? Talvez a psicologia superficial das terapias cognitivas comportamentais forneça um modelo para se pensar o novo "self" que emerge junto com o que alguns se referem como brainhood ${ }^{14}$, ou subjetividade cerebral, e o que nomeei como "individualidade somática" e o nascimento do "self" neuroquímico. Ou então o "self' psicológico vai se provar mais durável, e de alguma maneira necessário num período de intensificação do desejo e da administração de influências. É muito cedo para dizer. Mas, se a psicologia for substituída pela neurobiologia como a principal maneira de se entender a conduta humana e os fatores que a influenciam, uma coisa é certa - para tomar o lugar que foi aberto nos nossos sistemas de governo, nossas práticas de regulação e nossos regimes éticos, a neurobiologia também terá que se tornar uma "ciência social".

\section{Notas}

1. Tradução da palestra: Rose, N. (2007). Psychology as Social Science (E. R. P. Martins, Trad., A. M. Jacó-Vilela \& A. A. do Espírito Santo, Review). Paper presented at the Psychology as a Social Science Public Lecture Series 2006/7, Essex, UK. Retrieved December 12, 2007, from http:// www.psych.lse.ac.uk/socialpsychology/events/200607/other/ documents/NikRose_05_02_07.pdf

2. A palavra "distress" tem vários significados: distress na medicina, por exemplo, é um estresse causado por eventos adversos. Neste caso, é um tipo de sofrimento. (Nota do Tradutor)

3. Cyril Lodowic Burt (1883-1971) educador inglês conhecido por seus estudos sobre o efeito da hereditariedade na inteligência. (Nota do Tradutor)

4. Robert Blair (1859-1935) educador cuja maior contribuição para educação foi enquanto Oficial de Educação no London County Council (LCC), posto que manteve de 1904 até sua aposentadoria em 1924. (Nota do Tradutor)

5. Edição Brasileira: (1978). O normal e o patológico. Rio de Janeiro, RJ: Forense Universitária. (Nota do Tradutor)

6. Edição Brasileira: (1972). O que é Psicologia? In Tempo Brasileiro (pp. 30-31). (Nota do Tradutor)

7. Edição Brasileira: (1972). A Psicologia Social da indústria: Relações humanas na fábrica. São Paulo, SP: Atlas. (Original publicado em 1976). (Nota do Tradutor)

8. Awareness é uma reação perceptiva e cognitiva humana ou animal a um evento ou condição. Awareness não necessariamente significa entendimento, apenas uma habilidade de ser consciente, sentir ou perceber. (Nota do Tradutor)

9. Tennessee Valley Authority (TVA) é uma corporação federal nos EUA criada para prover navegação, controle de enchentes, eletricidade, manufatura de fertilizantes e desenvolvimento econômico no Vale do Tennessee uma região bastante afetada pela Grande Depressão. (Nota do Tradutor)

10. Unilever é uma multinacional anglo-neerlandesa líder em vendas de bens de consumo de produtos alimentícios, de higiene e de limpeza. (Nota do Tradutor)

11. Enterprise pode também ser traduzido como "iniciativa" ou "empreendimento". (Nota do Tradutor)

12. Edição Brasileira: (1961). Dinâmica de grupo: Pesquisa e teoria. São Paulo, SP: Herder. (Nota do Tradutor)

13. GP (General Practitioner) é uma especialidade médica caracterizada pela atenção integral à saúde e por levar em consideração a inserção do paciente na família e na comunidade. No Brasil, foi reconhecida pelo Ministério da Educação, por intermédio da Comissão Nacional de Residência Médica em 1981, com o nome de Medicina Geral e Comunitária. (Nota do Tradutor)

14. Uma tradução para "brainhood" seria "cerebralidade". (Nota do Tradutor) 


\section{Referências}

Este texto é uma palestra e, por esta razão, não possui uma bibliografia formal. Referências completas a todos os textos citados, no entanto, podem ser encontradas nesses livros do autor.

Rose, N. (1985). The psychological complex. London: Routledge. Rose, N. (1996). Inventing ourselves. Cambridge, MA: Cambridge University Press.

Rose, N. (1999). Governing the soul: The shaping of the private self (2nd. ed.). London: Free Associations. (Original publicado em 1989)

Nikolas Rose is the Martin White Professor of Sociology, and the Director of the London School of Economics and Political Science (LSE's) BIOS Centre for the Study of Bioscience, Biomedicine, Biotechnology and Society- University of London, United Kingdom.

n.rose@1se.ac.uk

Tradução da Palestra: Rose, N. (2007). Psychology as

Social Science. Paper presented at the Psychology as a

Social Science Public Lecture Series 2006/7, Essex, UK.

Psicologia como uma Ciência Social

Tradução: Emerson R. P. Martins

Revisão: Ana Maria Jacó-Vilela \& Adriana A. do Espírito Santo

Recebido: 14/05/2008

Aceite final: 20/06/2008 